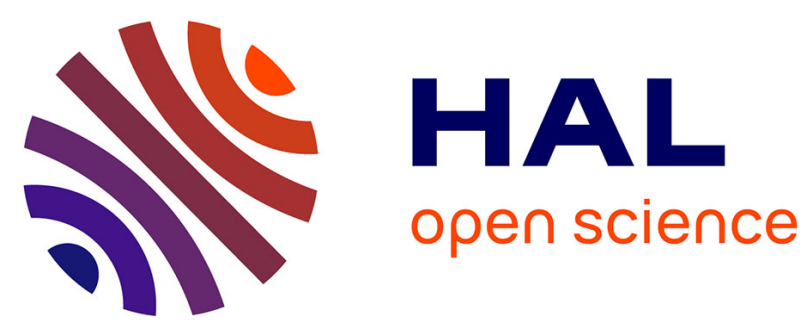

\title{
The Ultrastructure of Sanchytrium tribonematis (Sanchytriaceae, Fungi incertae sedis) Confirms its Close Relationship to Amoeboradix
}

Sergey Karpov, Andrey E Vishnyakov, David Moreira, Purificacion

Lopez-Garcia

\section{To cite this version:}

Sergey Karpov, Andrey E Vishnyakov, David Moreira, Purificacion Lopez-Garcia. The Ultrastructure of Sanchytrium tribonematis (Sanchytriaceae, Fungi incertae sedis) Confirms its Close Relationship to Amoeboradix. Journal of Eukaryotic Microbiology, 2019, 10.1111/jeu.12740 . hal-02365842

\section{HAL Id: hal-02365842 \\ https://hal.science/hal-02365842}

Submitted on 15 Nov 2019

HAL is a multi-disciplinary open access archive for the deposit and dissemination of scientific research documents, whether they are published or not. The documents may come from teaching and research institutions in France or abroad, or from public or private research centers.
L'archive ouverte pluridisciplinaire HAL, est destinée au dépôt et à la diffusion de documents scientifiques de niveau recherche, publiés ou non, émanant des établissements d'enseignement et de recherche français ou étrangers, des laboratoires publics ou privés. 


\title{
The Ultrastructure of Sanchytrium tribonematis (Sanchytriaceae, Fungi incertae sedis) Confirms its Close Relationship to Amoeboradix
}

\author{
Sergey A. Karpov ${ }^{a, b, c}$, Andrey E. Vishnyakov ${ }^{b}$, David Moreira ${ }^{c}$ \& Purificación López- \\ García $^{c}$ \\ a Zoological Institute, Russian Academy of Sciences, St. Petersburg 199034, Russia \\ ${ }^{b}$ St. Petersburg State University, St. Petersburg 199034, Russia \\ c Unité d'Ecologie, Systématique et Evolution, CNRS, Université Paris-Sud, Université \\ Paris-Saclay, AgroParisTech, 91400 Orsay, France
}

\begin{abstract}
Fungi encompass, in addition to classically well-studied lineages, an everexpanding diversity of poorly known lineages that include, among others, zoosporic chytrid-like parasites. According to recent phylogenetic analysis based on $18 \mathrm{~S}+28 \mathrm{~S}$ rRNA concatenated genes two unusual chytrid-like fungi Amoeboradix gromovi and Sanchytrium tribonematis form a monophyletic group, the family Sanchytriaceae, which represents a new divergent taxon that remains incertae sedis within Fungi. Zoospores of Amoeboradix gromovi contain one of the longest kinetosomes known in eukaryotic cells, which are composed of microtubular singlets or doublets. However, the ultrastructure of $S$. tribonematis, the type species of the genus had not been yet studied. Here, we provide the results of TEM investigations of zoospores and sporangia from two strains of $S$. tribonematis. The two strains are endowed with unusual features. Like in A. gromovi, amoeboid zoospores of $S$. tribonematis contain a long kinetosome composed of microtubular singlets, and the two orthogonal centrioles in their sporangia have nine microtubular singlets with an internal ring. The morphological and ultrastructural features of $S$. tribonematis are now included in the improved taxonomic diagnosis for this species.
\end{abstract}


In recent years, the generalized use of molecular phylogeny tools is unveiling an increasingly expanding diversity of microbial eukaryotes and fungi in particular. The combination of molecular phylogeny and electron microscopy has revealed a wide cryptic diversity of zoosporic fungi. Thus, in the past decade several new orders of chytridiomycetes, some of which had already been predicted based on molecular phylogeny analysis (James et al. 2006), have been formally described (Karpov et al. 2014; Letcher et al. 2006; Longcore and Simmons 2012; Mozley-Standridge et al. 2009; Simmons et al. 2009). At the same time, some organisms traditionally considered typical chytrids have dramatically changed their taxonomic classification to match their position in molecular phylogenetic trees. Thus, the former chytridiomycete genus Olpidium has been re-classified as an independent lineage related to the Zoopagomycota, one of the clades previously included within the now paraphyletic Zygomycota (James et al. 2006; Sekimoto et al. 2011).

Recently, we obtained $18 \mathrm{~S}$ and $28 \mathrm{~S}$ rRNA gene data for Amoeboradix gromovi, a chytrid-like fungus having peculiar traits and resembling the classical Rhizophydium anatropum. Surprisingly, phylogenetic analyses of these two markers showed that Amoeboradix formed a tight cluster with another chytrid-like organism, Sanchytrium tribonematis, branching in a basal position to the Glomeromycota and Dikarya cluster, albeit with low support (Karpov et al. 2018). The Amoeboradix-Sanchytrium clade is very divergent and represents a new fungal lineage.

However, so far only A. gromovi has been characterized morphologically and ultrastructurally, and it is therefore not possible to define synapomorphies for the family Sanchytriaceae. Amoeboradix possesses rather peculiar ultrastructural features, notably its amoeboid zoospores contain an extremely long $(2 \mathrm{~lm})$ and at the same time reduced kinetosome composed of singlets/doublets (not triplets) of microtubules (Karpov et al. 2018).

Light microscopy and ultrastructural data on S. tribonematis zoospores are still lacking despite this is the type species of the genus Sanchytrium and the family Sanchytriaceae Karpov et Aleoshin 2017. In particular, it would be necessary to study zoospore ultrastructure to explore whether the kinetosome structure shares the unusual features of Amoeboradix. To investigate this, we have studied the morphology of zoospores and sporangia in two strains of S. tribonematis: X-126 and X-128, both from the Culture Collection of Parasitic Protists of the Zoological Institute, Russian Academy of Science (CCPP ZIN RAS) (Malysheva et al. 2016). The two strains seemed to belong to the same species (Karpov et al. 2017); accordingly, we did not find any morphological differences in zoospores, cysts, and sporangia by light and electron microscopy. Based on the newly generated morphological data, we have identified synapomorphies for the Sanchytrium-Amoeboradix family and improved the species description of $S$. tribonematis Karpov et Aleoshin 2017 including more information on zoospore structure.

\section{MATERIAL AND METHODS}

The strains $X-126$ and $X-128$ of $S$. tribonematis (CCPP ZIN RAS) were maintained in culture on Tribonema gayanum Pasch. (strain $20 \mathrm{CALU}$ ) as the host. The host was grown in mineral medium 1 (KNO3, 2 g/L; KH2PO4, $0.3 \mathrm{~g} / \mathrm{L} ; \mathrm{MgSO} 4,0.15 \mathrm{~g} / \mathrm{L} ;$ EDTA, 10 $\mathrm{mg} / \mathrm{L} ; \mathrm{FeSO} 4,5 \mathrm{mg} / \mathrm{L} ; \mathrm{NaBO} 3,1.4 \mathrm{mg} / \mathrm{L} ;(\mathrm{NH} 4) 6 \mathrm{Mo} 7 \mathrm{O} 2,4.1 \mathrm{mg} / \mathrm{L} ; \mathrm{CaCl} 2,0.6 \mathrm{mg} / \mathrm{L}$; ZnSO4, $0.1 \mathrm{mg} / \mathrm{L}$; CuSO4, $50 \mathrm{mg} / \mathrm{L}$, Co(NO3)2, $20 \mathrm{mg} / \mathrm{L})$ at room temperature in the presence of white light. After inoculation with a strain of parasite, the co-culture was incubated for 1-2 wk to reach the maximum infection of host cells.

Light and DIC microscopy observations of living cultures were carried out on a Zeiss Axioplan microscope equipped with black and white MRm Axiocam. For electron microscopy, zoospores and sporangia were fixed with a mixture of $2 \%$ glutaraldehyde 
and $1 \%$ OsO4 prepared on the medium 1 for $40-50$ min on ice in dark. Material was concentrated by filtration through polycarbonate filter, embedded in $0.5 \%$ agar, rinsed in the same medium twice for 5 min. After rinsing the material was dehydrated in alcohol series and in propylen oxide and then embedded in Spurr resin (Sigma Aldrich, St. Louis, MO). Ultrathin sections were prepared using a Leica Ultracut ultratome with a diamond knife. After double staining, the sections were observed using a JEM 1400 (Jeol) microscope equipped with digital camera Olympus Veleta.

\section{RESULTS \\ Zoospore}

Amoeboid zoospores are typically 4-5 Im long and $3 \mathrm{Im}$ wide with few lipid globules. They produce thin filopodia at any place of the cell when crawling on the substrate (Fig. 1A-D). These amoeboid cells normally exhibit a broad and flat hyaline pseudopodium (lamellipodium) at the anterior end that can also form subfilopodia (Fig. 1A-D). Most zoospores have a tracking posterior pseudocilium of different lengths (up to $5 \mathrm{~lm}$ ), but this pseudocilium is rather labile and can be totally retracted.

Using serial ultrathin sections, we studied released zoospores (Fig. 1E-P). A nucleus occupies the center of the cell, lipid globules of medium size are associated with loosely granulated microbodies, forming a microbody-lipid complex (MLC) (Fig. 1E). Mitochondria with lamellar cristae locate more posteriorly and are often associated with a long kinetosome, 1.0-1.2 Im in length (Fig. 1F-J). A Golgi body is present near the nucleus, and a contractile vacuole at the cell periphery (Fig. 1E). The cytoplasm contains scattered ribosomes and star-shaped structures of about $50 \mathrm{~nm}$ in diameter consisting of six globular units (Fig. 1E,F). They might be rosettes of glycogen particles. Interestingly, one such particle is always present in the posterior half of the kinetosome (Fig. 1F).

The kinetosome is connected with a short centriole near the nucleus (Fig. 1E,J). The kinetosome grows on the base of the centriole from its proximal end, being on the same longitudinal axis with the latter (Fig. 1J). Both structures have a cart-wheel at their proximal end. The distal end of the kinetosome is anchored in the plasma membrane and has a partition, the transverse plate, and short transitional fibers (Fig. $1 \mathrm{H}, \mathrm{I}, \mathrm{N}, \mathrm{P}$ ). The kinetosome, which is $150-160 \mathrm{~nm}$ wide, is composed of nine single microtubules that extend along the whole kinetosome length (Fig. 1N,O). There is no obvious connection of these tubules to each other (Fig. 10), thus, they seem to be supported as a cylinder at the proximal end by cart-wheel structure and at the distal end by transverse plate. Only four of the nine microtubules continue into the pseudocilium, gradually reducing on the way to the tip (Fig. 1K-P).

\section{Sporangia}

Sporangia are spherical or slightly elongated, with a maximal diameter $10 \mathrm{Im}$. They have a smooth cell wall and usually one papilla (Fig. 2A,B). A straight or slightly branched rhizoid ca. 5-8 Im long and $0.5 \mathrm{Im}$ thick can be sometimes visible inside the alga (Fig. $2 \mathrm{~A}, \mathrm{C}, \mathrm{E})$. It normally enters the host in between the inner and outer half of the Tribonema cell wall (Fig. 2C).

The immature sporangium has several nuclei (Fig. 2D), which then divide during sporangial growth, producing tens of nuclei (Fig. 2E). The cell cytoplasm is filled with numerous spherical lipid droplets of different diameter often associated with small microbodies (Fig. 2D,E). Numerous mitochondria with predominantly flat cristae spread throughout the sporangium. The sporangial wall is rather thick (up to $200 \mathrm{~nm}$ ) and is composed of layered, more or less homogenous, material (Fig. 2D,E). Some vesicles ca. 200-300 $\mathrm{nm}$ in diameter contain dark material at different degrees of degradation (Fig. 2D). They are associated with lipid globules and probably take part in lipid utilization. 
The centriolar apparatus of the interphase nucleus in the sporangium consists of two orthogonal centrioles with radiating microtubules (Fig 3A,B). Each centriole is composed of nine microtubular singlets around an inner circle or cylinder (Fig. 3A insert). Before nuclear division the centrioles are oriented parallel to each other, each is located in its own pit on the nuclear surface and underlined with a so-called intranuclear component (INC) (Fig. 3A-D). The INC is known to serve as a microtubule-organizing center (MTOC) for the intranuclear mitotic spindle in chytrids (Ichida and Fuller 1968). Other stages of nuclear division were not studied.

\section{DISCUSSION}

Sanchytrium tribonematis is the type species for the divergent fungal family Sanchytriaceae, which contains only two monospecific genera, Sanchytrium and Amoeboradix. However its detailed morphology and ultrastructure have never been investigated. Here, we study for the first time the general morphology of $S$. tribonematis zoospores as well as zoospore and sporangia ultrastructure. Light microscopic observations are consistent with the features observed in the few images published earlier for this species (Karpov et al. 2017). We studied sporangia in three $S$. tribonematis strains, which vary slightly in the shape and number of papillae: X-126 has spherical sporangia with rare one or two papillae; X-127 has spherical sporangia with no papillae; X-128 has spherical to slightly elongated sporangia with one papilla. In general, $S$. tribonematis has a smaller and more round sporangium than A. gromovi, with one or, rarely, more papillae, and slightly bigger zoospores. Unlike Amoeboradix, Sanchytrium has small lipids globules in zoospores, which do not form a rosary chain. The pseudocilium is shorter in Sanchytrium; however its internal structure, studied here in transversal sections for the first time, cannot be compared with that of Amoeboradix, which remains to be analyzed. The kinetosome of $\mathrm{S}$. tribonematis is shorter and composed by microtubular singlets. Consequently, it is more reduced than in Amoeboradix (Table 1).

In spite of these small differences between Amoeboradix and Sanchytrium, they have generally similar morphology at the level of the amoeboid zoospores, which are both endowed with pseudocilium and an extraordinarily long and structurally reduced kinetosome composed of microtubule singlets/doublets, instead of triplets. Therefore, the morphological and ultrastructural features of both organisms support (i) their phylogenetic similarity and (ii) their divergent character with respect to other fungal lineages, as their shared traits are exceptionally unusual among studied zoosporic fungi.

Orthogonal centrioles composed of microtubular triplets have been shown at very early prophase for the blastocladiomycete Catenaria anguillulae Sorokin (Ichida and Fuller 1968). However, even in metaphase, its centrosome is composed of two orthogonal centrioles at each pole of the intact nucleus. The extranuclear component (ENC) attaches the centrioles to the nuclear envelope and the INC acts as a MTOC of the intranuclear spindle. We observed INC in the nuclei marking the early prophase in Sanchytrium but the centrioles were parallel to each other. In the absence of INC, i.e., in the interphase nucleus, the centrioles are orthogonal to each other.

Another difference from known features of fungal centrosomes is that the centrioles of $S$. tribonematis are composed of nine singlets, as its kinetosome, and has an internal ring. A nucleus associated organelle (NAO) with an internal ring has been described for the Zoopagomycota fungus Basidiobolus (McKerracher and Heath 1985), but it consists of a cylinder of 11-12 microtubular singlets, thus, it does not correspond to the centriole. Taking into account the more complete morphological data obtained in this study as compared to previous work (Karpov et al. 2017), we improve here the diagnoses of the genus Sanchytrium and the species S. tribonematis. 
Sanchytrium (Karpov et Aleoshin 2017) emend. Karpov 2019.

Parasite of algae. Sporangia epibiotic, spherical to ovate with one rarely more discharge papillae. Amoeboid zoospores with anterior lamellipodium; with (rarely without) pseudocilium; contains kinetosome composed of nine single microtubules 1-1.2 Im in length. Zoospores attach to algal cell wall, encyst, and penetrate host wall with a short rhizoid. Interphase nuclei in sporangia have a centrosome of two orthogonal centrioles composed by nine microtubular singlets and with an internal fibrillar ring.

Type Sanchytrium tribonematis Karpov et Aleoshin 2017

Sanchytrium tribonematis (Karpov et Aleoshin 2017) emend. Karpov 2019.

Sporangium round to ovate, smooth, $\sim 10 \mathrm{~lm}$ diam. with one or without discharge papilla; sessile on algal surface. Rhizoid slightly branched almost invisible inside host. Amoeboid zoospores $5.493 .3 \mathrm{Im}$ (maximum) with anterior lamellipodium producing subfilopodia, lateral and posterior filopodia; normally with posterior pseudocilium up to $5 \mathrm{~lm}$ in length supported by up to four microtubules.

\section{ACKNOWLEDGMENTS}

The LM and TEM study and image analysis supported by RSF grant 16-14-10302, and the strain cultivation and writing by ERC Advanced Grant "Protistworld" N. 322669 and "Plast-Evol" N.787904. The investigated strains have been cultivated at the Center for Culturing Collection of Microorganisms of Research park of St. Petersburg State University. We thank the Research Resource Center for Molecular and Cell Technologies (RRC MCT) at St. Petersburg State University (SPbSU) for access to the EM facilities

\section{LITERATURE CITED}

Ichida, A. A. \& Fuller, M. S. 1968. Ultrastructure of mitosis in the aquatic fungus Catenaria anguillulae. Mycologia, 60:141-155.

James, T. Y., Letcher, P. M., Longcore, J. E., Mozley-Standridge, S. E., Porter, D., Powell, M. J., Griffith, G. W. \& Vilgalys, R. 2006. A molecular phylogeny of the flagellated fungi (Chytridiomycota) and description of a new phylum (Blastocladiomycota). Mycologia, 98:860-871.

Karpov, S. A., Kobzeva, A. A., Mamkaeva, M. A., Mamkaeva, K. A., Mikhailov, K. V., Mirzaeva, G. S. \& Aeoshin, V. V. 2014. Gromochytrium mamkaevae gen. et sp. nov. and two new orders: Gromochytriales and Mesochytriales (Chytridiomycetes). Persoonia, 32:115-126.

Karpov, S. A., López-García, P., Mamkaeva, M. A., Tcvetkova, V. S., Vishnyakov, A. E., Klimov, V. I. \& Moreira, D. 2018. The chytrid- like parasites of algae Amoeboradix gromovi gen. et sp. nov. and Sanchytrium tribonematis belong to a new fungal lineage. Protist, 169:122-140.

Karpov, S. A., Mamanazarova, K. S., Popova, O. V., Aleoshin, V. V., James, T. Y., Mamkaeva, M. A., Tcvetkova, V. S., Vishnyakov, A. E. \& Longcore, J. E. 2017. Monoblepharidomycetes diversity includes new parasitic and saprotrophic species with highly intronized rDNA. Fungal Biol., 121:729-741.

Letcher, P. M., Powell, M. J., Churchill, P. F. \& Chambers, J. G. 2006. Ultrastructural and molecular phylogenetic delineation of a new order, the Rhizophydiales. Mycol. Res., 110:898-915.

Longcore, J. E. \& Simmons, D. R. 2012. The Polychytriales ord. nov. contains chitinophilic members of the rhizophlyctoid alliance. Mycologia, 104:276-294. 
Malysheva, M. N., Mamkaeva, M. A., Kostygov, A. Y., Frolov, A. O. \& Karpov, S. A. 2016. Culture collection of parasitic protists at the Zoological Institute RAS (CCPP ZIN RAS). Protistology, 10:26-42.

McKerracher, L. J. \& Heath, I. B. 1985. The structure of cycle of the nucleus-associated organelle in two species of Basidiobolus. Mycologia, 77:412-417.

Mozley-Standridge, S. E., Letcher, P. M., Longcore, J. E., Porter, D. \& Simmons, D. R. 2009. Cladochytriales - a new order in Chytridiomycota. Mycol. Res., 113:498-507.

Sekimoto, S., Rochon, A., Long, J. E., Dee, J. M. \& Berbee, M. L. 2011. A multigene phylogeny of Olpidium and its implications for early fungal evolution. BMC Evol. Biol., 11:331.

Simmons, D. R., James, T. Y., Meyer, A. F. \& Longcore, J. E. 2009. Lobulomycetales, a new order in the Chytridiomycota. Mycol. Res., 113:450-460. 

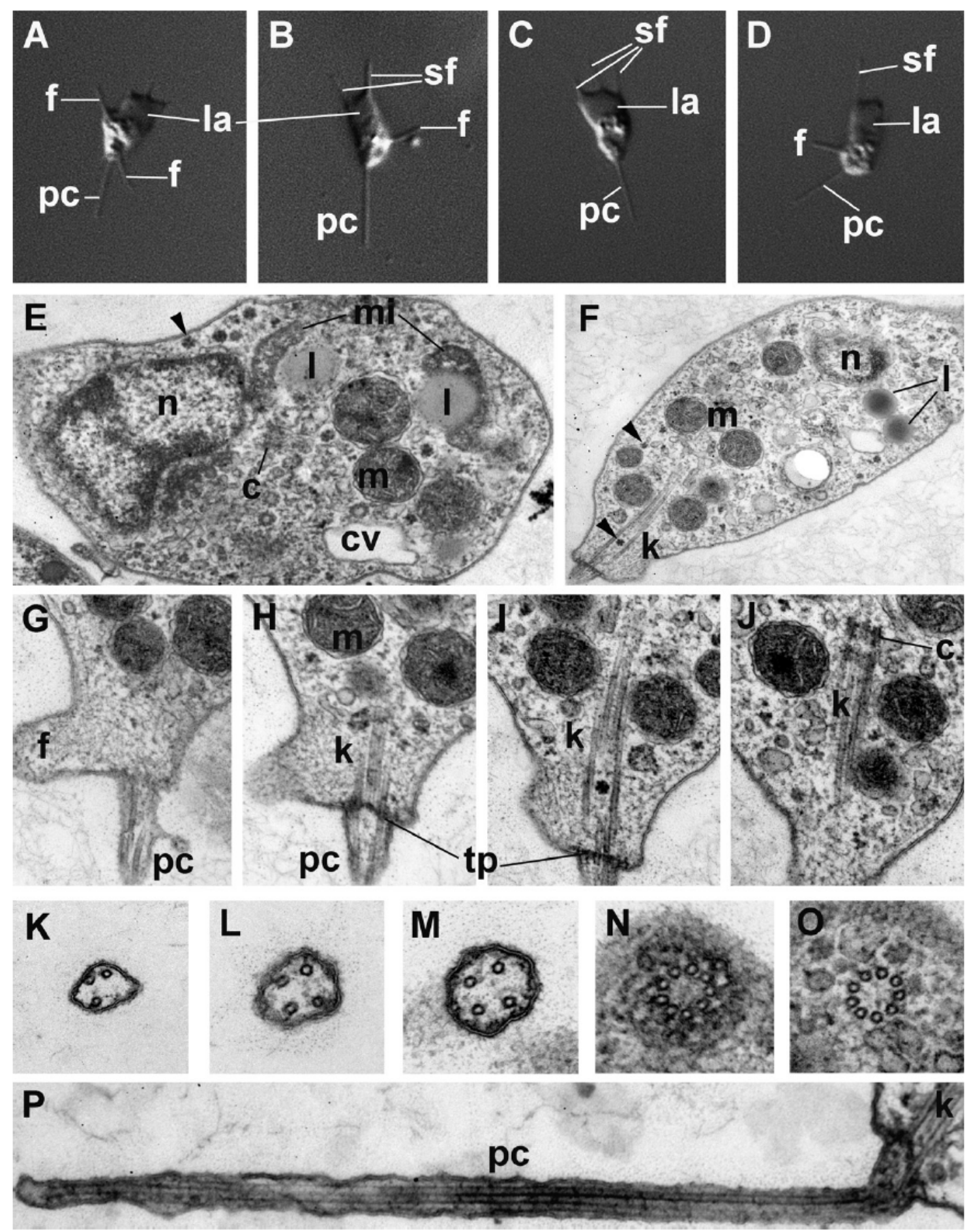

Figure 1 Zoospore structure of Sanchytrium tribonematis. A-D - DIC images of moving amoeboid zoospores. E and F - general cell structure, arrowheads show star-like particles. G-J - longitudinal sections (LS) of kinetosome and centriole of one cell. $\mathrm{K}-\mathrm{O}$ - consecutive transversal sections (TS) of pseudocilium $(\mathrm{K}-\mathrm{M})$, transition zone $(\mathrm{N})$ and kinetosome $(\mathrm{O}) . \mathrm{P}-\mathrm{LS}$ of kinetosome and pseudocilium. $\mathrm{c}=\mathrm{centriole}$; $\mathrm{cv}=$ contactile vacuole; $\mathrm{f}=$ filopodium; $\mathrm{k}=$ kinetosome; $\mathrm{I}=$ lipid globule; $\mathrm{la}=$ lamellipodium; $\mathrm{m}=$ mitochondrion; $\mathrm{mi}$ $=$ microbody; $n=$ nucleus; $p c=$ pseudocilium; $s f=$ subfilopodium; $t p=$ transverse plate. Scale bars: $A-D-5$ Im; E and F - $1 \mathrm{~lm}$; G-J - $300 \mathrm{~nm}$; K-O - $300 \mathrm{~nm}$; P - $300 \mathrm{~nm}$. 

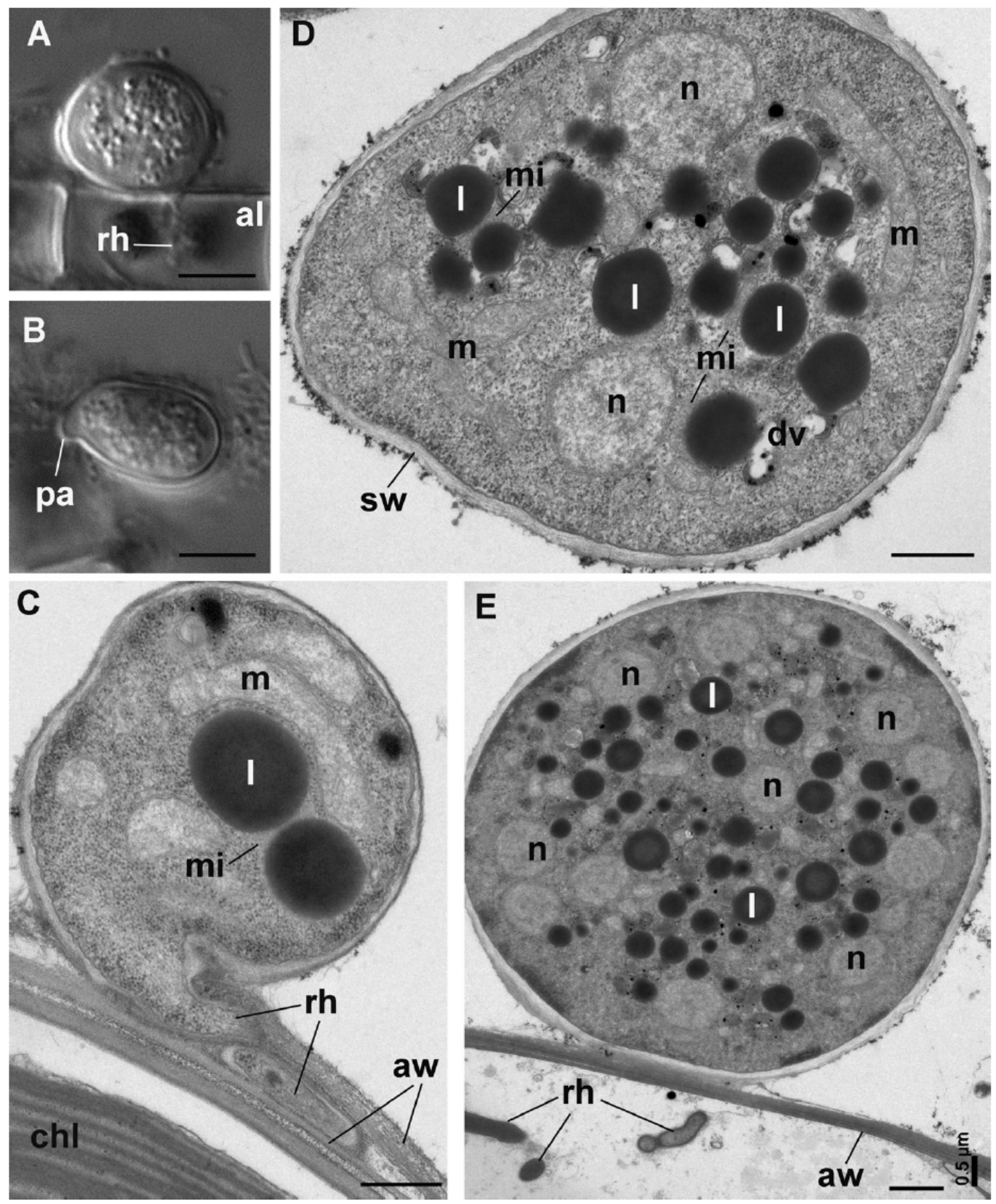

Figure 2 Sporangium structure of Sanchytrium tribonematis. A and B - DIC images of sporangium without (A) and with (B) papilla (pa), al = alga; rh = rhizoid. C-E - ultrastructure of young sporangium (C) with rhizoid (rh) penetrating between halves of algal wall (aw), chl = chloroplast; $\mathrm{mi}=$ microbody between two lipid globules (I), $m=$ mitochondrion; old sporangia $(D, E)$ with many nuclei $(n), d v=$ vesicles with degraded material; sw $=$ sporangial wall. Scale bars: $A$ and $B-5 \mathrm{~lm} ; C-500 \mathrm{~nm}$; D and $E-1 \mathrm{~lm}$. 
Table 1. Comparison of major phenotypic characters between Sanchytrium tribonematis and Amoeboradix gromovi

\begin{tabular}{|c|c|c|}
\hline Character/species & $\begin{array}{l}\text { Sanchytrium tribonematis (present paper) } \\
\text { Strains } X-126, X-128\end{array}$ & $\begin{array}{c}\text { Amoeboradix gromovi (Karpov et al. 2018) } \\
\text { Strain X-113 }\end{array}$ \\
\hline $\begin{array}{l}\text { Mature sporangium shape, size }(\mu \mathrm{m}) \\
\text { and number of papillae }\end{array}$ & Spherical (rarely elongated), 10, with a papilla & Elongated, $8-10 \times 16-18$, with $2-3$ papillae \\
\hline Zoospore max. size $(\mu \mathrm{m})$ & $3.3 \times 5.4$ & $3 \times 4$ \\
\hline Cyst size $(\mu \mathrm{m})$ & $3-4$ & $3-4$ \\
\hline Resting spore size $(\mu \mathrm{m})$ & No data & $6 \times 12$ \\
\hline Pseudocilium; length $(\mu \mathrm{m})$ & 5 & 8 \\
\hline Rhizoid & Slightly branching & Slightly branching \\
\hline Kinetosome structure; length $(\mu \mathrm{m})$ & Singlets; $1-1.2$ & Singlets/doublets; $1.8-2.2$ \\
\hline Glycogen (?) particles & + & + \\
\hline
\end{tabular}

